\title{
INDEKS KEANEKARAGAMAN HAYATI IKAN KEPE-KEPE (Chaetodontidae) DI PERAIRAN WAKATOBI, SULAWESI TENGGARA
}

\author{
Badrudin ", Sasanti"), R. Suharti "), Yahmantoro "), dan Imam Suprihanto "*)
}

\begin{abstract}
ABSTRAK
Kelompok ikan yang dianggap sebagai indikator bagi baik-buruknya kondisi lingkungan perairan terumbu karang adalah banyaknya jenis ikan kepe-kepe (Chaetodontidae) yang menghuni perairan karang tersebut. Data yang dianalisis merupakan sebagian hasil penelitian dengan metode transek garis (line intercept transect) yang dilaksanakan dalam rangka base line study Wakatobi. Penelitian dilakukan antara bulan September-Oktober 2001. Indeks keanekaragaman yang dihitung adalah dua Indeks Kekayaan (Richness Indices), empat Indeks Keanekaragaman (Diversity Indices) dan lima Indeks Kemerataan (Eveness Indices). Dengan demikian, dari satu set data sampel secara keseluruhan dapat disajikan sebanyak sembilan indeks dan dua angka diversity numbers $\left(\mathrm{N}_{1}\right.$ dan $\mathrm{N}_{2}$ ). Angka-angka indeks keanekaragaman hayati tersebut masingmasing baru merupakan angka tunggal yang dapat dianggap sebagai data dasar (base line data) untuk digunakan sebagai pembanding bagi kajian selanjutnya. Dengan membandingkan indeks-indeks tersebut dengan indeks dari perairan lain dapat disimpulkan bahwa Wakatobi mempunyai nilai keanekaragaman yang tertinggi. Spesies ikan kepe-kepe yang paling melimpah $\left(\mathrm{N}_{2}\right)$ adalah: Chaetodon kleini, Hemitaurichthys polylepsis, Chaetodon trifasciatus, Forecifiger longirostris, Heniochus varius, Chaetodon melanotus, $C$ punctatofasciatus, C. baronessa, dan $C$. vagabundus dengan indeks kelimpahan $\geq 37$ ekor. Enam spesies dari 15 spesies ikan kepe-kepe yang melimpah $\left(\mathrm{N}_{1}\right.$, termasuk $\mathrm{N}_{2}$ ) lainnya adalah: Chaetodon meyeri, $C$ ulietensis, C. unimaculatus, Heniochus monoceros, $\mathrm{C}$. adiergastus, $\mathrm{C}$. ornatisimus/C. trifascialis, dengan indeks kelimpahan sebesar $\geq 24$ ekor.
\end{abstract}

ABSTRACT: Biodiversity indices of butterfly fish (Chaetodontidae) in the waters of Wakatobi, Southeast Sulawesi. By: Badrudin, Sasanti, R. Suharti, Yahmantoro, and Imam Suprihanto

The availability of higher diversity of ornamental fish spesies of the family Chaetodontidae provides an indicator of bad or good for coral reefs environment. Data analyzed were part of the survey results obtained in the framework of the Wakatobi Base Line Study in the period of September-Oktober 2001. By using line intercept transect method the fishes found along the transect line were identified, counted, and recorded. The calculated indices include two Richness Indices, two Diversity Indices, two Diversity Numbers, and five Eveness Indices, so that, from one set of data sample, it is possible to present nine indices and two diversity numbers $\left(N_{1}\right.$ and $\left.N_{2}\right)$. The single observation numbers of indices provide a bench mark for base line data, comparable with the results of any further study in both the same survey area or other areas. By comparing with other indices collected from other areas, it was found that the coral reef environment in the waters of Wakatobi Islands was relatively good, as reflected by the higher occurrence of diversity indices. The most abundance of the indicator fish species found in the study area $\left(\mathrm{N}_{2}\right)$ was: Chaetodon kleini, Hemitaurichthys polylepsis, Chaetodon trifasciatus, Forecifiger longirostris, Heniochus varius, Chaetodon melanotus, C. punctatofasciatus, C. baronessa, and C. vagabundus, with the index of abundance of $\geq 37$ fish. The other six species from 15 abundance spesies ( $N_{1}$, include $N_{2}$ ) were: Chaetodon meyeri, C. ulietensis, C. unimaculatus, Heniochus monoceros, C. adiergastus, C. ornatisimus/ C. trifascialis, with the index of abundance of $\geq 24$ fish.

\section{KEYWORDS: biodiversity indices, ornamental fish, Wakatobi, Sulawesi Tenggara}

\section{PENDAHULUAN}

Tersedianya data dan informasi tentang indeks keanekaragaman hayati ikan dapat merupakan salah satu unsur penunjang bagi upaya pengelolaan dan pemanfaatan yang berlanjut dari kekayaan keanekaragaman hayati tersebut. Menurut Ludwig \& Reynold (1988), indeks keanekaragaman hayati merupakan karakterisasi dari hubungan-hubungan kelimpahan spesies dalam komunitas sumber daya. Selanjutnya dijelaskan bahwa keanekaragaman terdiri dari dua komponen yang berbeda, yaitu; 1) jumlah atau banyaknya spesies yang merupakan gambaran kekayaan spesies (spesies richness), dan 2) kemerataan (eveness), yaitu bagaimana kelimpahan spesies (individu atau biomassa) tersebut menyebar

\footnotetext{
") Peneliti pada Balai Riset Perikanan Laut, Jakarta

*) Peneliti pada Pusat Penelitian dan Pengembangan Oseanografi-LIPI, Jakarta

".) Freeland researcher
} 
di antara spesies-spesies. Gabungan informasi dari indeks kekayaan spesies dan kemerataan spesies dalam komunitas disebut indeks keanekaragaman (diversity indices). Adanya perubahan indeks tersebut dari waktu ke waktu merupakan indikasi adanya pengaruh terhadap komunitas yang ada.

Telah dimaklumi bahwa keanekaragaman hayati sangat penting karena berperan dalam mempertahankan kehidupan. Hilangnya keanekaragaman genetika atau biologi akan memperlemah kemampuan populasi untuk menyesuaikan diri terhadap perubahan lingkungan. Karena proses biologi dan fisika yang berlangsung di alam bersifat interaktif, hilangnya keanekaragaman hayati dapat mempercepat perubahan lingkungan ke arah yang tak terkirakan (Anonymous, 1993). Salah satu keunggulan komparatif perairan Indonesia adalah keanekaragaman hayati yang tingginya tak ternilai (Anonymous, 2002). Selanjutnya dijelaskan bahwa keanekaragaman sumber daya hayati di Indonesia, yang wilayah daratannya hanya sekitar $1,3 \%$ dari luas daratan bumi ini, menyimpan sekitar $17 \%$ dari seluruh spesies yang ada dipermukaan bumi, sehingga keanekaragaman tersebut dinyatakan sebagai 'megadiversity' (Watson \& Purbasari, 1993). Mengingat bahwa sekitar $70 \%$ wilayah Indonesia merupakan perairan, maka tidak diragukan lagi bahwa pada kawasan tersebut tersimpan keanekaragaman sumber daya perairan yang sangat tinggi.

Salah satu kelompok ikan yang dianggap merupakan indikator bagi baiknya kondisi terumbu karang adalah masih banyaknya ditemui jenis-jenis ikan kepe-kepe (Chaetodontidae) yang menghuni perairan karang tersebut (Anonymous, 2001). Tingginya keanekaragaman jenis ikan kepe-kepe, yang antara lain dinyatakan dalam bentuk indeks keanekaragaman, merupakan pertanda dari kondisi lingkungan terumbu karang yang baik.

Tulisan ini disusun sebagai konstribusi yang lebih bersifat complementary terhadap laporan yang telah disampaikan dalam rangka menunjang kegiatan COREMAP (Coral Reef Rehabilitation and Management Project). Hasil analisis ini dapat digunakan sebagai salah satu tambahan referensi bagi suatu kajian yang lebih bersifat base line study, dengan asumsi bahwa data sampel hasil penelitian yang dianalisis tersebut adalah proporsional dengan komunitas yang ada di alam. Dengan demikian, indeks keanekaragaman tersebut benar-benar merupakan gambaran keanekaragamanan hayati dari suatu perairan yang dikaji.

\section{BAHAN DAN METODE}

Data yang dianalisis adalah data tentang jenisjenis ikan kepe-kepe, yaitu salah satu jenis ikan dari famili Chaetodontidae yang dianggap sebagai ikan indikator bagi baik buruknya kondisi lingkungan terumbu karang. Data tersebut merupakan sebagian hasil penelitian yang telah dilaporkan oleh Tim Survei (Anonymous, 2001) Pusat Penelitian dan Pengembangan Oseanologi (P3O-LIPI) dalam rangka menunjang kegiatan COREMAP. Data tentang jenisjenis ikan kepe-kepe dikumpulkan melalui metode transek garis (line intercept transect), yang dilakukan antara bulan Nopember-Desember 2001, di perairan Wakatobi, Sulawesi Tenggara, yang secara geografis terletak pada posisi $05^{\circ} 15^{\prime} 00^{\prime \prime}-06^{\circ} 10^{\prime} 00^{\prime \prime}$ LS dan 123 ${ }^{\circ} 15^{\prime} 00^{\prime \prime}-124^{\circ} 45^{\prime} 00^{\prime \prime}$ BT.

Indeks keanekaragaman yang dihitung adalah Indeks Kekayaan (Richness Indices), Indeks Keanekaragaman (Diversity Indices) dan Indeks Kemerataan (Eveness Indices), sesuai dengan Ludwig \& Reynold (1988).

Indeks kekayaan spesies yang dihitung adalah; (1) Indeks Margalef, dengan rumus $\mathrm{R}_{1}=(\mathrm{S}-1) / \mathrm{ln}(\mathrm{n})$; dan (2) Indeks Menhinick, dengan rumus: $R_{2}=S / \sqrt{ }$; di mana $S=$ banyaknya spesies; $n=$ jumlah individu ikan untuk semua spesies. Indeks keanekaragaman meliputi; Indeks Simpson dengan rumus: $\lambda=\sum\left[\left(n_{i}\left(n_{i}-\right.\right.\right.$ 1) $/(n(n-1)] ;$ dan Indeks Shannon, $H=\sum\left[\left(n_{i} / n\right) \ln \left(n_{i}\right.\right.$ $/ n)$ ], dimana $n=$ total individu ikan untuk semua spesies, dan $n_{i}=$ jumlah ikan spesies $k e$ i. Selain kedua indeks tersebut telah pula dihitung besarnya Diversity Numbers dari Hill yaitu $\mathrm{N}_{1}$ dan $\mathrm{N}_{2}$, dimana $\mathrm{N}_{1}$ ditafsirkan sebagai banyaknya spesies yang cukup melimpah, sedangkan $N_{2}$ adalah banyaknya spesies yang paling melimpah. Rumus: $N_{1}=e^{H}$ dan $N_{2}=1 / \lambda$ dimana $H$ adalah Indeks Shannon dan $\lambda$ adalah Indeks Simpson. Indeks-indeks kemerataan yang dihitung adalah indeks Pielou, $E_{1}=[H / \ln (S)]$ Sheldon, $E_{2}=\left(e^{H} / S\right)$; Heip, $E_{3}=\left[\left(e^{H}-1\right) /(S-1)\right]$; Hill, $E_{4}=\left[(1 / \lambda) / e^{H}\right]$; dan Hill yang dimodifikasi, $E_{5}=\left\{[(1 / \lambda)-1] /\left(e^{H}-1\right)\right\}$, dimana $S=$ banyaknya spesies, $H=$ indeks Shannon, $\lambda$ = indeks Simpson dan $\mathrm{e}=$ bilangan natural.

\section{HASIL DAN BAHASAN}

\section{Perairan Wakatobi}

Perairan Wakatobi adalah perairan yang mengelilingi empat gugusan kepulauan yaitu: Kepulauan Wangi-wangi, Kaledupa, Tomea, dan Binongko. Topografi Kepulauan Wakatobi pada umumnya datar dikelilingi oleh mikro-atol dan perairan karang. Kedalaman perairan bervariasi, dengan bagian terdalam terletak di bagian barat maupun bagian timur yang mencapai sekitar 1.044 meter (Anonymous, 2001). Selanjutnya dijelaskan bahwa konfigurasi dari sebagian wilayahnya merupakan terumbu karang yang mendatar, kadang-kadang muncul di permukaan dengan beberapa kawasan mempunyai tubir-tubir yang tajam dengan biota laut yang sangat beragam, seperti kima, lola, penyu, karang keras, karang lunak, spons, lamun, ikan, dan lain-lain 
Gugusan kepulauan tersebut pernah dikenal sebagai Kepulauan Tukang Besi, yang berdasarkan Surat Keputusan Menteri Kehutanan No. 393/KptsVI/1996, tertanggal 30 Juli 1996, ditetapkan sebagai Taman Laut Nasional. Dari aspek pemanfaatan sumber daya ikan, perairan Wakatobi yang karena statusnya sebagai Taman Laut Nasional diduga merupakan perairan dengan tingkat pemanfaatan sumber daya ikan yang relatif masih rendah, terlepas dari upaya-upaya penangkapan ikan ilegal yang biasa terjadi di sebagian perairan karang di kawasan timur Indonesia.

Kepulauan Wakatobi terletak pada pertemuan antara Laut Banda dan Laut Flores yang relatif dalam. Secara administratif Kepulauan Wakatobi termasuk wilayah Kabupaten Buton, Propinsi Sulawesi Tenggara.

\section{Indeks Keanekaragaman}

Kekayaan spesies adalah banyaknya spesies (total number of spesies) yang ada dalam suatu komunitas (S). Informasi tentang $S$ tersebut tergantung kepada besarnya sampel dan waktu yang diperlukan untuk memperoleh sampel tersebut. Dari hasil transek garis telah diidentifikasi, dihitung, dan dicatat sekitar 30 spesies ikan dari famili Chaetodontidae, yang merupakan ikan indikator dari kondisi lingkungan terumbu karang.

Dewasa ini terdapat sejumlah indeks keanekaragaman dengan unit-unit indeks yang berbeda, sehingga sulit dibandingkan dan lebih-lebih untuk diinterpretasikan. Berdasarkan data sampel tersebut secara keseluruhan telah dihitung sebanyak 11 nilai, yaitu sembilan indeks dan dua angka $\left(\mathrm{N}_{1}\right.$ dan $\mathrm{N}_{2}$ ). Kesembilan indeks tersebut adalah dua indeks kekayaan (richness), 2 indeks keanekaragaman (diversity) dan 5 indeks kemerataan (eveness).

Angka-angka indeks yang diperoleh dari hasil perhitungan dan analisis data yang dikumpulkan dari perairan Wakatobi merupakan base line data (Tabel 1) yang dapat digunakan sebagai pembanding (benchmark) bagi hasil studi-studi lanjutan baik di perairan yang sama atau perairan lain. Jika dalam membandingkan data tersebut dijumpai adanya perubahan nilai indeks maka dapat diduga bahwa perubahan tersebut merupakan indikasi dari adanya pengaruh terhadap lingkungan komunitas yang ada.

Interpretasi para ahli terhadap angka-angka indeks tersebut yang mengarah kepada kriteria tentang tinggi-rendahnya keanekaragaman tampaknya lebih bersifat subyektif (Ludwig \& Reynold, 1988). Sebagai contoh adalah indeks keanekaragaman Shannon $(H)$. Jika: $\mathrm{H}<2$ keanekaragaman rendah; $2<\mathrm{H}<3$ keanekaragaman sedang; dan $\mathrm{H} \geq 3$ keanekaragaman tinggi.

Dengan asumsi bahwa sampel yang diperoleh adalah proporsional dengan populasi yang ada di alam, tampak bahwa populasi ikan kepe-kepe pada perairan karang Kepulauan Wakatobi, Sulawesi Tenggara, sampai dengan saat ini masih memiliki indeks kekayaan jenis $R_{1}=4,037 ; R_{2}=0,826$. Demikian juga halnya dengan indeks keanekaragaman, yaitu $\lambda=0,108$ dan $\mathrm{H}=2,718$ serta $N_{1}=15,154$ dan $N_{2}=9,247$. Diantara nilai-nilai

Tabel 1. Indeks kekayaan, indeks keanekaragaman, dan indeks kemerataan sumber daya ikan kepekepe (Chaetodontidae) di perairan Wakatobi

Table 1. Richness, diversity, and eveness indices of ornamental fish (Chaetodontidae) in the waters of Wakatobi

\begin{tabular}{|c|c|c|}
\hline No. & Indeks//ndices & Numbers \\
\hline \multirow{3}{*}{$\begin{array}{l}1 . \\
2 .\end{array}$} & Indeks Kekayaan (Richness index) & \multirow{3}{*}{$\begin{array}{l}4,037 \\
0,826\end{array}$} \\
\hline & Margalef $\quad\left(R_{1}\right)$ & \\
\hline & Menhinick $\quad\left(\mathrm{R}_{2}\right)$ & \\
\hline \multirow{5}{*}{$\begin{array}{l}3 . \\
4 . \\
5 . \\
6 .\end{array}$} & Indeks Keanekaragaman (Diversity index) & \multirow{5}{*}{$\begin{array}{c}0,108 \\
2,718 \\
15,154 \\
9,247\end{array}$} \\
\hline & Simpson $\ldots \ldots \ldots \ldots \ldots \ldots \ldots(\lambda)$ & \\
\hline & Shannon $\ldots \ldots \ldots \ldots \ldots \ldots \ldots(\mathrm{H})$ & \\
\hline & Hill diversity number...... $\left(\mathrm{N}_{1}\right)$ & \\
\hline & $\ldots \ldots \ldots\left(\mathrm{N}_{2}\right)$ & \\
\hline \multirow{6}{*}{$\begin{array}{l}7 . \\
8 . \\
9 . \\
10 . \\
11 .\end{array}$} & Indeks Kemerataan (Eveness index) & \multirow{6}{*}{$\begin{array}{l}0,799 \\
0,505 \\
0,488 \\
0,610 \\
0,583\end{array}$} \\
\hline & Pielou $\ldots \ldots \ldots \ldots . \ldots \ldots \ldots . . . \ldots\left(E_{1}\right)$ & \\
\hline & Sheldon $\ldots \ldots \ldots \ldots \ldots \ldots \ldots\left(E_{2}\right)$ & \\
\hline & Heip $\quad \ldots \ldots \ldots \ldots \ldots \ldots \ldots \ldots\left(E_{3}\right)$ & \\
\hline & Hill $\ldots \ldots \ldots \ldots \ldots \ldots \ldots \ldots,\left(E_{4}\right)$ & \\
\hline & Modified Hill $\ldots \ldots \ldots \ldots \ldots . . . . .\left(E_{5}\right)$ & \\
\hline
\end{tabular}


tersebut yang paling mudah untuk diinterpretasi secara ekologis adalah Diversity numbers dari Hill yang dikenal sebagai $N_{1}$ dan $N_{2}$, di mana $N_{1}$ ditafsirkan sebagai banyaknya spesies yang cukup melimpah, sedangkan $\mathrm{N}_{2}$ adalah banyaknya spesies yang paling melimpah.

Nilai $N_{1}$ dan $N_{2}$ hasil transek garis di kawasan Wakatobi tampak cukup tinggi. Mengacu ke data komposisi hasil transek (Lampiran 1 dan 2) dapat dilihat bahwa di perairan Wakatobi di mana nilai $\mathrm{N}_{1}=$ 15,154, mempunyai implikasi bahwa paling tidak terdapat 15 spesies ikan kepe-kepe yang melimpah dan $N_{2}=9,247$ atau paling sedikit terdapat sekitar 9 spesies ikan yang paling melimpah. Spesies ikan kepe-kepe yang paling melimpah tersebut adalah; 1) Chaetodon kleini, 2) Hemitaurichthys polylepsis, 3) Chaetodon trifasciatus, 4) Forecifiger longirostris, 5) Heniochus varius, 6) Chaetodon melanotus, 7) C. punctatofasciatus, 8) C. baronessa, dan 9) C. vagabundus dengan indeks kelimpahan sebesar $\geq 37$ ekor. Enam spesies dari 15 spesies ikan kepekepe yang melimpah $\left(N_{1}\right.$, termasuk $\left.N_{2}\right)$ lainnya adalah: 1) Chaetodon meyeri, 2) C. ulietensis, 3) C. unimaculatus, 4) Heniochus monoceros, 5)
C. adiergastus, 6) C. ornatisimus/C.trifascialis, dengan indeks kelimpahan sebesar $\geq 24$ ekor (Lampiran 1).

Jika kelimpahan semua spesies ikan dalam sampel adalah sama, maka secara intuisi indeks kemerataannya maksimum. Indeks tersebut akan menurun ke arah nol apabila kelimpahan relatif dari spesies-spesies tersebut jauh dari merata.

Karena indeks tersebut masih merupakan angka tunggal, maka untuk memudahkan interpretasi dapat dilakukan dengan cara membandingkan angka-angka indeks tersebut secara horisontal, yaitu membandingkan antara satu perairan dengan perairan lain baik yang berada pada posisi geografis yang sama atau berbeda. Dengan metode yang sama indeks kekayaan, keanekaragaman, dan kemerataan hasil tangkapan empat alat alat tangkap menetap di perairan Indragiri Hilir, Riau telah dihitung dan dilaporkan oleh Badrudin et al. (2001), dan hasil tangkapan rawai dasar di perairan Selatan Kepulauan Aru (Badrudin et al., 2001a), yang keduanya juga masing-masing merupakan data dasar (base line data). Secara geografis ketiga perairan tersebut terletak pada posisi yang sangat berbeda.

Tabel 2.

Posisi geografis perairan kawasan survei

Table 2. Geographic position of surveyed areas

\begin{tabular}{llll}
\hline No. & \multicolumn{1}{c}{ Perairan/Waters area } & Lintang/Latitude (S) & Bujur/Longitude (E) \\
\hline 1. & Wakatobi, Sulawesi Tenggara & $05^{\circ} 15^{\prime} 00^{\prime \prime}-06^{\circ} 10^{\prime} 00^{\prime \prime}$ & $123^{\circ} 15^{\prime} 00^{\prime \prime}-124^{\circ} 45^{\prime} 00^{\prime \prime}$ \\
2. & Indragiri Hilir, Riau & $00^{\circ} 00^{\prime} 00^{\prime \prime}-01^{\circ} 00^{\prime} 00^{\prime \prime}$ & $103^{\circ} 00^{\prime} 00^{\prime \prime}-104^{\circ} 00^{\prime} 00^{\prime \prime}$ \\
3. & Aru, Maluku & $06^{\circ} 30^{\prime} 00^{\prime \prime}-08^{\circ} 00^{\prime} 00^{\prime \prime}$ & $133^{\circ} 00^{\prime} 00^{\prime \prime}-136^{\circ} 00^{\prime} 00^{\prime \prime}$ \\
\hline
\end{tabular}

Tabel 3. Perbandingan indeks kekayaan, indeks keanekaragaman, dan indeks kemerataan sumber daya di perairan Wakatobi, Selatan Aru, dan Indragiri Hilir

Table 3. Comparison of the richness, diversity, and eveness indices in the waters of Wakatobi, Southern Aru, and Indragiri Hilir

\begin{tabular}{|c|c|c|c|c|c|c|c|}
\hline \multirow{5}{*}{ No. } & \multirow[b]{2}{*}{ Waters } & Wakatobi & Aru $\left.{ }^{\top}\right)$ & \multicolumn{4}{|c|}{ Indragiri Hilir ${ }^{2}$ ) } \\
\hline & & Transect & $\begin{array}{l}\text { Bottom } \\
\text { long line }\end{array}$ & $\begin{array}{c}\text { Gombang } \\
\text { net }^{3} \text { ) }\end{array}$ & $\begin{array}{l}\text { Jermal } \\
\text { net }^{3} \text { ) }\end{array}$ & $\begin{array}{c}\text { Kelong } \\
\left.\text { net }^{3}\right)\end{array}$ & $\begin{array}{l}\text { Togo } \\
\text { net }^{3} \text { ) }\end{array}$ \\
\hline & No. Of spesies (S) & 30 & 34 & 26 & 21 & 24 & 10 \\
\hline & $N=\Sigma n_{i}($ fish $)$ & 1318 & 1708 & 29287 & 7678 & 20174 & 7740 \\
\hline & Indices & & & & & & \\
\hline & Richness & & & & & & \\
\hline 1. & Margalef $\left(R_{1}\right)$ & 4,037 & 3,426 & 2,430 & 2,236 & 2,310 & 1,005 \\
\hline 2. & Menhinick $\left(R_{2}\right)$ & 0,826 & 0,641 & 0,192 & 0,240 & 0,169 & 0,114 \\
\hline & Diversity & & & & & & \\
\hline 3. & Simpson $(\lambda)$ & 0,108 & 0,114 & 0,118 & 0,781 & 0,181 & 0,825 \\
\hline 4. & Shannon $(\mathrm{H})$ & 2,718 & 2,673 & 2,540 & 0,650 & 2,014 & 0,400 \\
\hline 5. & Hill number: $\left(\mathrm{N}_{1}\right)$ & 15,154 & 14,482 & 12,680 & 1,920 & 7,493 & 2,282 \\
\hline 6. & $\ldots \quad \ldots \ldots\left(\mathrm{N}_{2}\right)$ & 9,247 & 8,919 & 8,506 & 1,280 & 5,525 & 1,212 \\
\hline & Eveness & & & & & & \\
\hline 7. & Pielou $\quad\left(E_{1}\right)$ & 0,799 & 0,815 & 0,780 & 0,214 & 0,634 & 0,358 \\
\hline 8. & Sheldon & 0,505 & 0,548 & 0,488 & 0,091 & 0,312 & 0,228 \\
\hline 9. & Heip & 0,488 & 0,209 & 0,467 & 0,046 & 0,282 & 0,142 \\
\hline 10. & Hill $\quad\left(E_{4}\right)$ & 0,610 & 0,613 & 0,671 & 0,667 & 0,737 & 0,531 \\
\hline 11. & Modified Hill $\left(E_{5}\right)$ & 0,583 & 0,477 & 0,643 & 0,304 & 0,697 & 0,165 \\
\hline
\end{tabular}

Keterangan/Remarks: ${ }^{1 /}$ Badrudin et al., (2001); ${ }^{21}$ Badrudin et al., (2001a); ${ }^{3}$ Four types of trapnet 
Perairan Wakatobi merupakan Taman Laut Nasional. Perairan selatan Kepulauan Aru yang sebagian dasar perairannya merupakan kawasan perairan karang merupakan daerah penangkapan ikan-ikan dasar berukuran besar, sedangkan perairan Indragiri Hilir merupakan perluasan (extension) dari perairan estuarin dengan muara-muara sungai yang cukup besar. Berbeda dengan perairan Wakatobi yang tingkat pemanfaatannya masih relatif rendah, sumber daya ikan dan udang di perairan Indragiri Hilir diduga telah dieksploitasi secara intensif, terutama pada periode sebelum diberlakukannya Keppres $39 / 1980$ tentang pelarangan trawl. Sebagaimana dimaklumi bahwa perairan sepanjang pantai timur Sumatera, dengan sejumlah muara sungai merupakan daerah penangkapan udang-ikan demersal yang potensial.

Dengan asumsi bahwa sampel yang diperoleh adalah proporsional dengan populasi yang ada di alam, tampak bahwa populasi ikan kepe-kepe pada perairan karang Kepulauan Wakatobi, Sulawesi Tenggara, sampai dengan saat ini masih memiliki indeks kekayaan jenis yang tertinggi, sebagaimana tercermin dari nilai $R_{1}=4,037$ dan $R_{2}=0,826$.

Indeks Simpson terletak antara 0-1, dimana makin besar indeks tersebut makin rendah indeks keanekaragaman hayati. Nilai indeks Simpson perairan Wakatobi pada periode penelitian ini adalah $\lambda=0,108$, yang merupakan angka indeks yang terendah yang mencerminkan keanekaragaman yang tinggi dibandingkan dengan indeks yang sama dari kedua perairan lainnya. Tingginya keanekaragaman tersebut juga sesuai dengan nilai indeks lainnya, seperti indeks Shannon, $\mathrm{H}=2,718$ serta $\mathrm{N}_{1}=15,154$ dan $N_{2}=9,247$ dibandingkan dengan indeks keanekaragaman populasi ikan yang tertangkap di perairan Aru dan Indragiri Hilir, Riau (Tabel 3).

\section{KESIMPULAN}

Dari uraian di atas dapat dikemukakan beberapa kesimpulan berikut:

1. Tersedianya data dan informasi tentang indeks keanekaragaman hayati ikan dapat merupakan salah satu unsur penunjang bagi pengelolaan dan pemanfaatan yang berlanjut dari kekayaan keanekaragaman hayati tersebut.

2. Untuk memudahkan interpretasi indeks-indeks tersebut telah dilakukan perbandingan antara perairan Kepulauan Wakatobi, selatan Kepulauan Aru, dan Indragiri Hilir, di mana ditemukan bahwa perairan Wakatobi merupakan perairan dengan keanekaragaman hayati ikan yang tertinggi.

3. Angka-angka indeks keanekaragaman hayati dari ketiga perairan tersebut masing-masing baru merupakan angka tunggal yang dapat dianggap sebagai data dasar (base line data) untuk digunakan sebagai pembanding bagi kajian selanjutnya.

4. Jenis-jenis ikan kepe-kepe yang melimpah di perairan Wakatobi adalah; Chaetodon kleini, Hemitaurichthys polylepsis, Chaetodon trifasciatus, Forecifiger longirostris, Heniochus varius, Chaetodon melanotus, C. punctatofasciatus, C. baronessa, C. vagabundus, C. meyeri, C. ulietensis, C. unimaculatus, Heniochus monoceros, C. adiergastus, dan C. Ornatisimus/ C.trifascialis.

\section{DAFTAR PUSTAKA}

Anonymous, 1993. National strategy for marine biodiversity management. Technical appendix. In R. A. Watson (Ed). Marine Biodiversity Management. Final Report on Advisorship. EMDI, Min. of State for the Environment, RI and Dalhousie University. Canada. 52 pp.

Anonymous., 2001. Base line study Wakatobi, Sulawesi Tenggara. CRITC-NASIONAL COREMAP. 132 pp.

Anonymous, 2002. Riset unggulan strategis bidang kelautan dan perikanan. Makalah Bagian Perencanaan. Badan Riset Kelautan dan Perikanan. Rapat Kerja Teknis. Bali Oktober 2002. Badan Riset Kelautan dan Perikanan. Dep. Kelautan dan Perikanan, 20 pp.

Badrudin, B. Sumiono, \& T.S. Murtoyo. 2001. Spesies composition and diversity of tidal trap net catches in the waters on Indragiri Hilir, Riau, Indonesia. Indonesian Fisheries Research Jjournal, 7(1): 47-53.

Badrudin, B. Sumiono, \& N. Wirdaningsih., 2001. Komposisi dan keanekaragaman hasil tangkapan rawai dasar di perairan selatan Kepulauan Aru. Makalah disajikan pada Seminar Laut Nasional III Ikatan Sarjana Oseanologi (ISOI) 29-31 Mei 2001. Jakarta. 10 pp.

Ludwig, J.A. \& J.F. Reynolds. 1988. Statistical ecology: A primer on methods and computing. John Wiley \& Sons. New York, 337 pp.

Watson, R. \& I.A.N. Purbasari. 1993. Marine biodiversity in Indonesia. In R. A.Watson (Ed). Marine Biodiversity Management. Final Report on Advisorship. EMDI, Min. of State for the Environment, RI and Dalhousie University. Canada, 8 pp. 
Lampiran 1. Jenis-jenis ikan hias (Chaetodontidae) hasil transek di perairan Wakatobi (Anonymous, 2001)

Appendix 1. Ornamental fish species recorded from line intercept transec in the Wakatobi waters, Southeast Sulawesi (Anonymous, 2001)

\begin{tabular}{|c|c|c|c|}
\hline No. & Ornamental Fish Species & ni & $\%$ \\
\hline 1 & Chaetodon adiergastos & 25 & 1,90 \\
\hline 2 & C. auriga & 9 & 0,68 \\
\hline 3 & C. baronessa & 39 & 2,96 \\
\hline 4 & C. bennetti & 22 & 1,67 \\
\hline 5 & C. citrinellus & 19 & 1,44 \\
\hline 6 & C. ephippium & 14 & 1,06 \\
\hline 7 & C. kleini & 329 & 24,96 \\
\hline 8 & C. lineolatus & 8 & 0,61 \\
\hline 9 & C. Iunula & 1 & 0,08 \\
\hline 10 & C. semeion & 15 & 1,14 \\
\hline 11 & C. speculum & 15 & 1,14 \\
\hline 12 & C. melanotus & 52 & 3,95 \\
\hline 13 & C. meyeri & 32 & 2,43 \\
\hline 14 & C. ocellicaudus & 17 & 1,29 \\
\hline 15 & C. ornatissimus & 24 & 1,82 \\
\hline 16 & C. oxicephalus & 1 & 0,08 \\
\hline 17 & C. punctatofasciatus & 46 & 3,49 \\
\hline 18 & C. rafflesii & 7 & 0,53 \\
\hline 19 & C. trifascialis & 24 & 1,82 \\
\hline 20 & C. trifasciatus & 113 & 8,57 \\
\hline 21 & C. ulietensis & 31 & 2,35 \\
\hline 22 & C. unimaculatus & 28 & 2,12 \\
\hline 23 & C. vagabundus & 37 & 2,81 \\
\hline 24 & Coradion altivelis & 2 & 0,15 \\
\hline 25 & Hemitaurichthys polylepsis & 200 & 15,17 \\
\hline 26 & Heniochus chrysostomus & 20 & 1,52 \\
\hline 27 & H. monoceros & 27 & 2,05 \\
\hline 28 & $H$. varius & 66 & 5,01 \\
\hline 29 & H. singularis & 4 & 0,30 \\
\hline \multirow[t]{2}{*}{30} & Forcifiger longirostris & 91 & 6,90 \\
\hline & Total & 1318 & 100,00 \\
\hline
\end{tabular}


Lampiran 2. Prosedur perhitungan indeks-indeks keanekaragaman hayati (Ludwig \& Reynold, 1988) Appendix 2. Procedure for calculation of biodiversity indices (Ludwig \& Reynold, 1988)

\begin{tabular}{|c|c|c|c|}
\hline Ikan Karang Indikator *) & ni & $n i^{*}(n i-1)$ & $(n i / n)^{*} \operatorname{Ln}(n i / n)$ \\
\hline Chaetodon adiergastos & 25 & 600 & $-0,075$ \\
\hline C. auriga & 9 & 72 & $-0,034$ \\
\hline C. baronessa & 39 & 1482 & $-0,104$ \\
\hline C. bennetti & 22 & 462 & $-0,068$ \\
\hline C. citrinellus & 19 & 342 & $-0,061$ \\
\hline C. ephippium & 14 & 182 & $-0,048$ \\
\hline C. kleini & 329 & 107912 & $-0,346$ \\
\hline C. lineolatus & 8 & 56 & $-0,031$ \\
\hline C. Iunula & 1 & 0 & $-0,005$ \\
\hline C. semeion & 15 & 210 & $-0,051$ \\
\hline C. speculum & 15 & 210 & $-0,051$ \\
\hline C. melanotus & 52 & 2652 & $-0,128$ \\
\hline C. meyeri & 32 & 992 & $-0,090$ \\
\hline C. ocellicaudus & 17 & 272 & $-0,056$ \\
\hline C. ornatissimus & 24 & 552 & $-0,073$ \\
\hline C. oxicephalus & 1 & 0 & $-0,005$ \\
\hline C. punctatofasciatus & 46 & 2070 & $-0,117$ \\
\hline C. rafflesii & 7 & 42 & $-0,028$ \\
\hline C. trifascialis & 24 & 552 & $-0,073$ \\
\hline C. trifasciatus & 113 & 12656 & $-0,211$ \\
\hline C. ulietensis & 31 & 930 & $-0,088$ \\
\hline C. unimaculatus & 28 & 756 & $-0,082$ \\
\hline C. vagabundus & 37 & 1332 & $-0,100$ \\
\hline Coradion altivelis & 2 & 2 & $-0,010$ \\
\hline Hemitaurichthys polylepsis & 200 & 39800 & $-0,286$ \\
\hline Heniochus chrysostomus & 20 & 380 & $-0,064$ \\
\hline H. monoceros & 27 & 702 & $-0,080$ \\
\hline$H$. varius & 66 & 4290 & $-0,150$ \\
\hline H. singularis & 4 & 12 & $-0,018$ \\
\hline Forcifiger longirostris & 91 & 8190 & $-0,185$ \\
\hline Total & 1318 & 187710 & $-2,718$ \\
\hline
\end{tabular}


